\title{
Pentaerythritol tetranitrate (sustained action) in acute myocardial infarction
}

\author{
D. J. Newell ${ }^{1}$ and Clinical Collaborators ${ }^{2}$
}

A multicentre trial of pentaerythritol tetranitrate (sustained action) $80 \mathrm{mg}$. b.i.d. in the 3 months after an acute myocardial infarction is described. Included in the trial were 346 patients, and at 6 months, the mortality rates in the treated and control group were almost identical at 23 per cent.

In young male patients, however, a favourable result to pentaerythritol tetranitrate (PETN) was obtained, supporting the finding of Oscharoff, who studied a somewhat differently defined group of young men. In women over 70 , however, mortality in the treated group was significantly higher than in controls.

Mortality following acute myocardial infarctions remains high. Hyperbaric oxygen (Cameron et al., 1965), glucose insulin and potassium (Paulley et al., 1967; Medical Research Council, 1968), and propranolol (Snow, 1965; Balcon et al., 1966; Multicentre Trial, 1966; Clausen et al., 1966; Norris, Caughey, and Scott, 1968) have their proponents, but controlled trials in the references cited have not indicated an unequivocal reduction in mortality. The role of anticoagulants in the immediate post-infarction period is established (Lancet, 1967; Merskey and Drapkin, 1965; Estes and Smith, 1966). Lumb, Singletary, and Hardy (1962) and Lumb and Hardy (1963) have described the value of pentaerythritol tetranitrate in the establishment of collateral circulation after occlusion of the coronary artery in the pig. In the human, sustained action pentaerythritol tetranitrate provides a dosage of $80 \mathrm{mg}$. (20 mg. immediately, the remainder over 12 hours), and is administered twice daily. The sustained action form of presentation will be abbreviated to PETN in this paper. It has been used as an adjunct therapy in a controlled trial by Oscharoff (1964) in the postinfarction period in male patients under the age of 65 , suffering their first infarction. The mortality within three weeks was only 4 per

Received 17 July 1969.

1 Professor of Medical Statistics, The Medical School, Newcastle upon Tyne.

2 Dr. J. Black (Warrington), Dr. C. Bremer (Sunderland), Dr. R. J. Calvert (Burnley), Dr. C. Davidson (Bradford), Dr. D. Freeman (Warrington), Dr. G. T. Gooding (Leeds), Dr. A. A. McI. Nicol (Sunderland), Dr. W. S. Suffern (Harrogate), Dr. R. H. Vasey (Sunderland), and Dr. A. A. Williams (Middlesbrough). cent in 50 men treated with PETN, compared with 22 per cent in 50 controls. Such a remarkable result merits confirmation in a larger series.

\section{Patients and methods}

The present paper describes a multicentre controlled trial of PETN as an addition to the usual therapy in each co-operating hospital.

Ten clinicians in eight centres took part, contributing in all 346 patients with definite acute myocardial infarction.

Diagnosis The fundamental diagnostic question which the physician asked himself was, 'Is this a patient whom I would willingly expose to PETN or to placebo, along with the usual range of analgesics, sedatives, anticoagulants, and oxygen, according to my current practice?'

The essential feature was a fresh myocardial infarction. For inclusion in the trial, treatment with PETN or Dummy must have started within 48 hours of the infarct. In 74 per cent of the cases included it had started within 24 hours, but an additional 9I cases were included where a further day had passed before the patient had been admitted and treatment had begun. In 9 cases included, the exact time of the infarct was not known, but it was under $\mathbf{4 8}$ hours.

With this early treatment, the diagnosis could not be confirmed immediately, and a number of cases originally admitted to the trial were withdrawn because the diagnosis of an infarct could not be confirmed on serial electrocardiograms. A total of 346 cases with infarctions is included in this analysis, and a further 126 cases were withdrawn, mainly because the diagnosis was not confirmed. One case was withdrawn on account of severe side effects, a patient who had previously reacted against three other cardiovascular drugs acting on the vascular system. No restriction was made on the history of previous infarction, angina, or diabetes, and the frequency 
TABLE I Clinical findings on admission

\begin{tabular}{|c|c|c|c|}
\hline \multicolumn{2}{|c|}{$\operatorname{Age}(y r$.$) and sex$} & \multirow{3}{*}{$\begin{array}{l}\begin{array}{l}\text { No. of } \\
\text { patients }\end{array} \\
\begin{array}{l}53 \\
88\end{array}\end{array}$} & \multirow{2}{*}{$\begin{array}{l}\text { Per cent } \\
\text { of total }\end{array}$} \\
\hline$<50$ & $\mathbf{M}$ & & \\
\hline $50-59$ & $\mathbf{M}$ & & $32 \cdot 5$ \\
\hline $60-69$ & $\mathbf{M}$ & 95 & $35 \cdot 1$ \\
\hline \multirow[t]{2}{*}{$70+$} & $\mathbf{M}$ & 35 & $12 \cdot 9$ \\
\hline & Total & 271 & 100 \\
\hline$<60$ & $\mathbf{F}$ & $2 I$ & $28 \cdot 0$ \\
\hline $60-69$ & $\mathbf{F}$ & 33 & $44 \cdot 0$ \\
\hline \multirow[t]{2}{*}{$70+$} & $\mathbf{F}$ & $2 \mathrm{I}$ & $28 \cdot 0$ \\
\hline & Total & 75 & 100 \\
\hline \multicolumn{4}{|c|}{ Previous infarctions } \\
\hline Non & & 264 & $76 \cdot 3$ \\
\hline One & & 67 & 19.4 \\
\hline Two & & 13 & $3 \cdot 8$ \\
\hline Thre & & 2 & 0.6 \\
\hline \multicolumn{4}{|c|}{ History } \\
\hline Angi & & 224 & $64 \cdot 7$ \\
\hline Diab & setes & 17 & 4.9 \\
\hline \multicolumn{4}{|c|}{ 'Clinical shock' } \\
\hline \multirow{2}{*}{\multicolumn{2}{|c|}{ on admission }} & 102 & $29 \cdot 5$ \\
\hline & & Mean & $S D$ \\
\hline \multirow{3}{*}{\multicolumn{2}{|c|}{$\begin{array}{l}\text { Systolic BP (mm. Hg) } \\
\text { Diastolic BP (mm. Hg) } \\
\text { Pulse rate on admission (min.) }\end{array}$}} & 143 & $\pm 26 \cdot 7$ \\
\hline & & 97 & $\pm 17 \cdot 2$ \\
\hline & & 86 & $\pm 22 \cdot 7$ \\
\hline
\end{tabular}

of these items is also shown in Table I which gives the clinical findings on admission.

\section{Treatments, and allocation to treatments}

Each patient was allocated to either PETN or indistinguishable placebo tablets. The PETN tablets contained $80 \mathrm{mg}$. pentaerythritol tetranitrate, and the dosage for each patient was I tablet every 12 hours, for a total of 12 weeks. Treatment started as soon as the patient was admitted to hospital, and was continued on an out-patient basis after discharge.

The axes of stratification for the random allocation were hospital and 'history'. Three 'history' categories were defined for this purpose: first attack without history of angina, first attack with history of angina, and subsequent attack. For each of these categories in each hospital, a dispensary list was prepared on which the allocation to PETN or Dummy was indicated. As soon as a patient was selected as suitable for the trial, a 'blind' prescription was made out by the physician, which the dispensary then interpreted according to the list. Thus neither the patient nor the physician knew which treatment the patient was receiving. This randomization and the subsequent withdrawal of patients
TABLE 2 Other treatments used during hospital stay

\begin{tabular}{|c|c|c|c|}
\hline & & PETN & Dummy \\
\hline \multirow[t]{6}{*}{ (a) } & Analgesics & & \\
\hline & None & $5 I$ & 55 \\
\hline & Narcotics ${ }^{\star}$ alone & 108 & 95 \\
\hline & Narcotics with others & 13 & II \\
\hline & Other analgesics & 9 & 4 \\
\hline & $x^{2}=2 \cdot 3, \quad$ d.f. $=3, \quad p$ & $>0.5$ not & \\
\hline \multirow[t]{8}{*}{ (b) } & Sedatives & & \\
\hline & None & 54 & 53 \\
\hline & Barbiturates alone & 82 & 74 \\
\hline & Barbiturates with others & 15 & I0 \\
\hline & Non-barbiturate hypnotics & 15 & 14 \\
\hline & Phenothiazine derivatives & 8 & 7 \\
\hline & Morphia & 5 & 6 \\
\hline & Others & 2 & $\mathbf{I}$ \\
\hline
\end{tabular}

(c) Anticoagulants

None $\quad 43 \quad 39$

Phenindione alone

Phenindione after heparin

Phenprocoumon after

$\begin{array}{ll}32 & 40 \\ 48 & 42\end{array}$

heparin

Warfarin after heparin

Heparin alone

Warfarin alone

Phenprocoumon alone

$$
x^{2}=3.6, \text { d.f. }=4, \quad \mathrm{p}>0.3 \text { not sig. }
$$

(d) Oxygen

$\begin{array}{lrr}\text { Administered } & 23 & 17 \\ \text { None } & 158 & 148\end{array}$

* 'Narcotic' analgesics in this classification are morphine and its derivatives, pethidine, and other synthetic drugs of addiction: other analgesics included drugs classified as nonbarbiturate hypnotics, phenothiazine derivatives, antihistamines, antiemetics, coronary vasodilators, and 'other analgesics'.

in whom the diagnosis was not confirmed, led to I8I patients on PETN and I65 patients on Dummy being included in the trial.

Other treatments used during the patient's stay in hospital were also recorded, and are shown in Table 2, subdivided according to the trial treatment (PETN or Dummy), and to the nature of the other treatments: analgesic, sedative, or anticoagulant. To summarize the very large number of other drugs used, they have been classified on the basis of the headings in Medindex (Jan.-March 1966). No special monitoring or 'intensive care' was arranged for these patients.

The types of analgesics given were similar in the PETN and Dummy groups. In all, $227(66 \%)$ of the patients received a narcotic (as defined in Table 2) occasionally with another analgesic. This proportion varied 
widely from hospital to hospital. The hospital with the largest number of patients in the trial gave narcotics to 45 per cent of patients, but 82 per cent of patients received them at the next largest hospital.

There were no significant differences between the two treatment groups in the proportions of patients who received the different types of sedatives or anticoagulants, nor those who received oxygen.

\section{Comparison of treatment groups before treatment}

Statistical comparisons disclosed no significant differences between PETN and Dummy groups in the following respects: age and sex, blood pressure, pulse rate, incidence of shock, number of infarctions, and history of angina and diabetes. Among the non-significant differences was only one conspicuous feature: 34 men aged under 50 were included in the PETN group, and only 19 in the Dummy group. Since prognosis is better in young patients, this tends to bias the over-all result in favour of PETN. Since the other treatments given in hospital to the PETN and Dummy patients also did not differ significantly, the trial yielded two similar groups, in whom a fair comparison of the effects of PETN could be made.

\section{Comparison of treatment groups while in hospital (first $2 \mathrm{I}$ days)}

(a) Mortality Table 3 (a) shows that 13.8 per cent of the PETN cases, and 14.5 of the Dummy cases died within the first 2I days. These figures include 13 and 12 cases, respectively, who died within the first 3 days, and may not have had time to obtain any effect from PETN. The number and timing of the later deaths in the first 3 weeks are very similar for the two treatments.

(b) Minimum systolic pressure in first 14 days As an indication of the presence of shock during hospital stay, the minimum systolic pressure recorded at the routine morning blood pressure readings in the first I4 days was analysed, for all patients who survived 14 days. Table 3 (b) shows that almost identical proportions showed readings below $100 \mathrm{~mm}$. Hg ( $18.6 \%$ PETN, and $18.3 \%$ Dummy), and that the distributions of minimum pressures for the two groups were very similar. For the patients who died between 4 and 14 days, the mean minimum systolic pressures recorded were PETN I04, Dummy I08; again not a significant difference.

Thus on the criteria of mortality, and minimum systolic pressure we are unable
TABLE 3 Comparisons during hospital stay

\begin{tabular}{|c|c|c|c|}
\hline & & PETN & Dummy \\
\hline \multirow{10}{*}{ (a) 1} & \multicolumn{3}{|l|}{ Mortality } \\
\hline & Day $\mathbf{r}$ & 6 & 5 \\
\hline & 92 & 5 & 4 \\
\hline & "3 & 2 & 3 \\
\hline & " 4-7 & 3 & 7 \\
\hline & " 8-14 & 5 & 3 \\
\hline & , I5-2I & 4 & 2 \\
\hline & Survived 21 days & $\begin{array}{l}156 \\
(86.2 \%)\end{array}$ & $\begin{array}{l}\text { I4I } \\
(85.5 \%)\end{array}$ \\
\hline & $\begin{array}{l}\text { Mean survival of deaths } \\
\text { under } 2 \mathrm{I} \text { days }\end{array}$ & $\begin{array}{l}6 \cdot 3 \\
\text { days }\end{array}$ & $\begin{array}{l}5 \cdot 3 \\
\text { days }\end{array}$ \\
\hline & Mortality under 21 days (\%) & 13.8 & $14 \cdot 5$ \\
\hline \multirow{8}{*}{ (b) } & \multicolumn{3}{|c|}{$\begin{array}{l}\text { Minimum systolic pressure in first } 14 \text { days of } \\
\text { survivors for } 14 \text { days }\end{array}$} \\
\hline & \multicolumn{3}{|l|}{$\begin{array}{l}\text { Minimum systolic } B P \\
\quad(\mathrm{~mm} . \mathrm{Hg})\end{array}$} \\
\hline & $60-79$ & 2 & 2 \\
\hline & $80-99$ & 27 & 24 \\
\hline & $100-119$ & 85 & 73 \\
\hline & $120-139$ & 34 & $3 I$ \\
\hline & $140+$ & 8 & 12 \\
\hline & Not recorded & 4 & $\mathbf{I}$ \\
\hline \multirow{2}{*}{\multicolumn{2}{|c|}{$\begin{array}{l}\text { Per cent below } 100 \mathrm{~mm} . \mathrm{Hg} \\
\text { Mean minimum systolic } \\
\text { BP }\end{array}$}} & 18.6 & $18 \cdot 3$ \\
\hline & & $112 \cdot 5$ & $113 \cdot 7$ \\
\hline \multicolumn{4}{|c|}{$t=0.61, \quad$ d.f. $=296, \quad \mathrm{p}>0.5$ not sig. } \\
\hline
\end{tabular}

to confirm the findings of Oscharoff (1964), who by $2 I$ days after the infarct found a mortality difference of 4 per cent with PETN against 22 per cent with Dummy and a difference in shock occurring after admission of 8 per cent with PETN against 24 per cent with Dummy. His criterion of 'shock' was a minimum systolic pressure of under 90 $\mathrm{mm}$. $\mathrm{Hg}$, but such pressures were rarely recorded in the present trial, and were certainly not more frequently recorded on the Dummy treatment.

(c) Side-effects Patients were not specifically asked about side-effects, in order to avoid producing them by suggestion. Apart from one case withdrawn from the trial, sideeffects were reported by only 20 patients, equally divided between the PETN and Dummy groups.

\section{Comparison of treatment groups at 6-month follow-up}

The most important criterion of success of treatment is survival. Table 4 (a) shows that $76 \cdot 2$ per cent of patients were alive at 6 months after PETN and $77^{\circ} \circ$ per cent were alive after Dummy. Only 5 patients included were not examined at the follow-up, but their 
survival and general health at 6 months after the infarct have been ascertained from their general practitioners. The time to death in the quarter of patients who did not survive for 6 months was also similar in the PETN and Dummy groups.

Within the 6-month period, 9.4 per cent of PETN cases and 5.5 per cent of Dummy cases had a further infarct, a non-significant difference. The time distribution to a further infarct was also similar.

At the 6-month re-examination, every surviving patient was assessed by the clinician. Table 4 (c) shows that 44.8 per cent of PETN patients were recorded as 'well at 6 months', against 38.8 per cent of Dummy patients. When the two groups 'well' and 'fair' at 6 months are put together, 58 per cent of PETN patients, and 5I per cent of Dummy patients are included. This difference is not statistically significant. Angina at 6 months was reported for $17 \cdot 1$ per cent of those treated with PETN and 23.6 per cent of the Dummy patients.

\section{Factors relating to mortality within six months}

Since the PETN or Dummy treatment did not affect the over-all mortality of these patients, the two treatment groups can be combined to provide a larger sample, which can be examined for major factors related to mortality.

Mortality was closely related to age at onset, but there was no evidence of a sex difference in mortality, when age was taken into consideration. For each sex, death occurred within 6 months for about ro per cent of the under 60's, 25 per cent of the 60-69's, and nearly 50 per cent of the patients aged 70 or over. These results are fairly similar to those achieved in an intensive care unit (Lawrie et al., 1967), but as our patients were admitted on average longer after the infarction, strict comparison is not possible. For the same reason, we cannot claim that our mortality rate in hospital was better than that of 19 per cent at another intensive care unit (Thomas, Jewitt, and Shillingford, 1968).

A pulse rate of over 95 beats a minute is associated with a mortality of nearly 50 per cent; lower pulse rates have 15 per cent mortality.

First infarctions have a better prognosis (mortality of $20 \%$ ) than subsequent infarctions (mortality of $33 \%$ ).

No significant mortality associations were found with the hospital centre in the trial, with the time between infarction and treat-
TABLE 4 Comparison of longer term effects:

follow-up to 6 months

\begin{tabular}{|c|c|c|c|}
\hline & & PETN & Dummy \\
\hline \multirow[t]{5}{*}{ (a) } & Mortality & & \\
\hline & Died within 2I days (Table 3a) & 25 & 24 \\
\hline & Died $22-99$ days & II & 9 \\
\hline & $\begin{array}{l}\text { Died 100-193 days } \\
\text { Survived } 6 \text { months }\end{array}$ & $\begin{array}{l}7 \\
138(76 \cdot 2 \%)\end{array}$ & $127(77 \cdot 0 \%)$ \\
\hline & Mortality under 6 months (\%) & $23 \cdot 8$ & $23 \cdot 0$ \\
\hline \multirow[t]{7}{*}{ (b) } & Time to further infarct & & \\
\hline & $<$ I month & $\mathbf{I}$ & 2 \\
\hline & I month & 4 & - \\
\hline & 2 months & 3 & 2 \\
\hline & 3 months & 3 & $\mathbf{I}$ \\
\hline & 4 months & 4 & $\mathbf{I}$ \\
\hline & $\begin{array}{l}5 \text { months }-6 \text { months } \\
\text { No further infarct in } 6 \text { months }\end{array}$ & $\stackrel{2}{164(90 \cdot 6 \%)}$ & ${ }_{156(94.5 \%)}^{3}$ \\
\hline
\end{tabular}

(c) Clinician's assessment at 6 months

Died before 6 months

Well, no after effects mentioned

Fair

Angina

Other comments *

Seen, not assessed

$\begin{array}{ll}43(23 \cdot 8 \%) & 38(23 \cdot 0 \%) \\ 81(44 \cdot 8 \%) & 64(38.8 \%) \\ 24(13.3 \%) & 20(12 \cdot 1 \%) \\ 31(17 \cdot 1 \%) & 39(23.6 \%) \\ 2 & 3 \\ 0 & 1\end{array}$

$x^{2}=2.91, \quad$ d.f. $=3, \quad \mathrm{p}>0.3$ not sig.

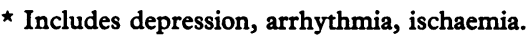

TABLE 5 Effect of PETN on mortality in age-sex groups

\begin{tabular}{|c|c|c|c|c|c|c|}
\hline \multicolumn{2}{|c|}{ Age (yr.) and sex } & \multicolumn{2}{|c|}{$P E T N$} & \multicolumn{2}{|c|}{ Dummy } & \\
\hline & & Died & Total & Died & Total & \\
\hline $\begin{array}{c}<50 \\
50-59 \\
60-69 \\
70+ \\
<60 \\
60-69 \\
70+\end{array}$ & $\begin{array}{l}\mathbf{M} \\
\mathbf{M} \\
\mathbf{M} \\
\mathbf{M} \\
\mathbf{F} \\
\mathbf{F} \\
\mathbf{F}\end{array}$ & $\begin{array}{c}\text { I }(3 \%) \\
7(17 \%) \\
13(25 \%) \\
10(53 \%) \\
1(8 \%) \\
4(27 \%) \\
7(86 \%)\end{array}$ & $\begin{array}{r}34 \\
41 \\
52 \\
19 \\
12 \\
15 \\
8\end{array}$ & $\begin{array}{l}5(26 \%) \\
7(15 \%) \\
9(21 \%) \\
7(44 \%) \\
1(11 \%) \\
6(33 \%) \\
3(23 \%)\end{array}$ & $\begin{array}{r}19 \\
47 \\
43 \\
16 \\
9 \\
18 \\
13\end{array}$ & $p=0.04$ \\
\hline
\end{tabular}

ment, with blood pressures on admission, or with a history of angina or diabetes.

\section{Analysis of the effect of PETN on sub- groups of patients}

Though the over-all result with PETN was no better than with Dummy, we wondered whether it had been effective in specific subgroups of the population. In searching for such subgroups, there is a risk of finding the 'chance' I-in-20 significant result in 20 comparisons, and the exercise might be referred to as hypothesis forming, rather than hypothesis testing.

The main difference between the present study and that of Oscharoff (1964) is that his 
patients were all male, suffering from their first infarct, and aged under 65. Our patients were of all ages, both sexes, and some had previous infarcts. This provided a broadbased study, and is fully justified, but it is not directly comparable to Oscharoff's results.

Among men under 60 suffering their first infarction in the present study, 6 out of 63 (10\%) died after PETN and 6 out of $5 I$ $(12 \%)$ died after Dummy, clearly a nonsignificant difference.

Ignoring the factor of first or subsequent infarction, a further analysis (Table 5) was made of the relation between PETN and sixmonth survival in each of 7 age-sex groups. In 2 of these, statistically significant results were found, though the numbers were small.

In men aged under 50, I death in 34 PETN cases was significantly better than 5 deaths in I9 Dummy cases. On the other hand, in women aged 70 or over, 7 deaths in 8 PETN cases was significantly worse than only 3 deaths in 13 Dummy cases. In none of the other age-sex groups was there any hint of an association between PETN and mortality or survival.

We conclude, in the light of Oscharoff's (1964) findings and our own, that there may be some case for the use of PETN in younger men, and in the absence of further studies, a contraindication for its use in the oldest women.

\section{Discussion}

Several of the treatments for acute myocardial infarction listed in the introduction to this paper have at first shown remarkably satisfactory results, usually in uncontrolled trials, occasionally in controlled trials (e.g. Snow, 1965). PETN follows this pattern of a very significant reduction in mortality in one trial (Oscharoff, 1964), and relatively little effect in the present trial. The unusual feature of this trial is the apparent value to younger men, counterbalanced by the apparent lethality of PETN to older women. While it is tempting to dismiss one of these two results as a chance occurrence, there is no rational basis for deciding which should be so dismissed. When a group comparable with Oscharoff's (young men suffering their first infarction) is constructed from the present trial, there is again no apparent value of PETN in reducing mortality.

This trial suggests that further trials in young men - in whom there may possibly be latent collateral channels in the myocardium - would be worth while, but old age in women appears to be a contraindication.

We thank Messrs. William R. Warner and Co. Ltd. for the supply of tablets of PETN (Peritrate S.A.) and placebo, and Dr. D. D. H. Craig for his assistance and skill in co-ordination, $\mathrm{Mr}$. R. A. McNay for data processing, Mrs. D. Weightman for statistical analysis, and Mrs. S. Lyons for secretarial control of the records.

\section{References}

Balcon, R., Hewitt, D. E., Davies, J. H. P., and Oram, S. (1966). A controlled trial of propranolol in acute myocardial infarction. Lancet, 2, 917.

Cameron, A. J. V., Gibb, B. H., Ledingham, I. McA., and McGuinness, J. B. (1965). A controlled clinical trial of hyperbaric oxygen in the treatment of acute myocardial infarction. In Hyperbaric Oxygenation, pp. 277-288. Ed. by I. McA. Ledingham. Livingstone, Edinburgh.

Clausen, J., Felsby, M., Jørgensen, F. S., Nielsen, B. L., Roin, J., and Strange, B. (1966). Absence of prophylactic effect of propranolol in myocardial infarction. Lancet, 2, 920.

Estes, J. W., and Smith, D. L. (1966). The summary retrospective assessment of anticoagulants in myocardial infarction. American fournal of the Medical Sciences, 251, 249.

Lancet (1967). Leading article. Anticoagulant treatment for myocardial infarction. 2, 405 .

Lawrie, D. M., Greenwood, T. W., Goddard, M., Harvey, A. C., Donald, K. W., Julian, D. G., and Oliver, M. F. (1967). A coronary-care unit in the routine management of acute myocardial infarction. Lancet, 2, 109.

Lumb, G. D., and Hardy, L. B. (1963). Collateral circulation and survival related to gradual occlusion of the right coronary artery in the pig. Circulation, 27, 717 .

-, Singletary, H. P., and Hardy, L. B. (1962). Collateral circulation following experimental gradual narrowing of the coronary arteries. Angiology, I3, 463 .

Medical Research Council Working-Party (1968). Potassium, glucose, and insulin treatment for acute myocardial infarction. Lancet, 2, 1355 .

Merskey, C., and Drapkin, A. (1965). Anticoagulant therapy. Blood, 25, 567.

Multicentre Trial (I966). Propranolol in acute myocardial infarction. Lancet, 2, 1435.

Norris, R. M., Caughey, D. E., and Scott, P. J. (1968). Trial of propranolol in acute myocardial infarction. British Medical fournal, 2, 398.

Oscharoff, A. (1964). Pentaerythritol tetranitrate, as adjunct therapy in the immediate postinfarction period. Angiology, 15, 505.

Paulley, J. W., Jones, R., Hughes, J. P., Day, J. L., and Crowle, P. M. (1967). G.I.K. therapy in myocardial infarction. Lancet, 2, 72I and II 50.

Snow, P. J. D. (1965). Effect of propranolol in myocardial infarction. Lancet, 2, $55 \mathrm{I}$

Thomas, M., Jewitt, D. E., and Shillingford, J. P. (I968). Analysis of I 50 patients with acute myocardial infarction admitted to an intensive care and study unit. British Medical fournal, 1, 787. 